\title{
Assessment of the knowledge, attitude and practice of pharmacovigilance by pharmacists in two states in south- eastern Nigeria
}

\author{
Jude A Udoye ${ }^{1}$, Raymond I Ozolua ${ }^{1 *}$, Jude Nwokike ${ }^{2}$ \\ ${ }^{1}$ Department of Pharmacology and Toxicology, University of Benin, Benin City 300001, Nigeria, ${ }^{2}$ United States Pharmacopeial \\ Convention, 12601 Twinbrook Parkway, Rockville MD 20852-1790, USA
}

*For correspondence: Email: ozolua@uniben.edu; Tel: +234-8023528166

Sent for review: 20 June 2017

Revised accepted: 11 November 2017

\begin{abstract}
Purpose: To evaluate knowledge, attitude and practice (KAP) of pharmacovigilance (PV) and adverse drug reactions (ADRs) reporting among community and hospital pharmacists in Abia and Imo States of Nigeria.

Methods: A cross-sectional survey was done using a validated questionnaire distributed among hospital and community pharmacists in the two States.

Results: Out of the 227 copies of the questionnaire administered, 169 (74.4\%) were usable. Only 22\% of all the pharmacists had postgraduate qualification but $78.0 \%$ had more than five years postqualification experience. All respondents were aware of the concept of PV; $73.4 \%$ had seen a patient with ADR while $17.7 \%$ had not seen the ADR reporting form in use in Nigeria. Only $24.3 \%$ had officially reported an ADR. Factors that affected reporting were lack of incentive (52.1\%), role conflict (69.2\%), and role overload (72.8\%). Mean score for KAP-related questions was higher among hospital pharmacists than their community counterparts.

Conclusion: The study has shown that while all pharmacists were aware of $P V$, the attitude and practice of many of them constituted a challenge and accounted for poor level of reporting.
\end{abstract}

Keywords: Adverse drug reactions, Community pharmacists, Hospital pharmacists, National Pharmacovigilance Centre

\begin{abstract}
This is an Open Access article that uses a funding model which does not charge readers or their institutions for access and distributed under the terms of the Creative Commons Attribution License (http://creativecommons.org/licenses/by/4.0) and the Budapest Open Access Initiative (http://www.budapestopenaccessinitiative.org/read), which permit unrestricted use, distribution, and reproduction in any medium, provided the original work is properly credited.
\end{abstract}

Tropical Journal of Pharmaceutical Research is indexed by Science Citation Index (SciSearch), Scopus, International Pharmaceutical Abstract, Chemical Abstracts, Embase, Index Copernicus, EBSCO, African Index Medicus, JournalSeek, Journal Citation Reports/Science Edition, Directory of Open Access Journals (DOAJ), African Journal Online, Bioline International, Open-J-Gate and Pharmacy Abstracts

\section{INTRODUCTION}

Adverse drug reactions (ADRs) rank among the leading causes of death in many countries [1-3]. The annual health bills arising from drug-related adverse events have been estimated to be very high $[4,5]$. For example the estimated cost of drug related morbidity and mortality in the United States was \$US177.4 billion in the year 2000 [6].
The Nigerian drug safety scenario is worse than what obtains in developed countries because of widespread irrational use of medicines $[7,8]$. In addition, the presence of unregulated drug markets, weak regulatory systems, lack of enforcement of the regulations, and inadequate resources to monitor safety of medicines [9] are major issues in Nigeria. 
Pharmacists have been recognized as very easily accessible health professionals $[10,11]$ and their core competence of being experts in drugs puts them in a good position to assist in promoting the concept of pharmacovigilance. The community and hospital pharmacists directly relate with patients much more than their counterparts in the industry, regulatory agencies and the academia [11]. They are therefore very relevant in pharmacovigilance.

Spontaneous reporting of adverse drug reactions has been acknowledged as the cornerstone of pharmacovigilance [12]. It is a system in which case reports of adverse drug events are voluntarily submitted by health professionals and subjects to the National Pharmacovigilance Centre [13]. Its success depends on the awareness, motivation and enthusiasm of healthcare practitioners [12,14]. Reporting of ADR is voluntary and the number of reports per year is often low thereby leading to the suggestion that it should be mandatory but this has always been opposed by health workers because they view it as an extra burden on their busy schedules [15]. Because of their specialized skills, community and hospital pharmacists, help to establish and strengthen pharmacovigilance structures in their places of practice through spontaneous reporting as has been observed in Canada [12].

Nigeria falls far below the recommended 200 reports per million population per year [7]. Many reactions to drugs are often not recognized and even when they are recognized, they are not reported [16]. None of the very few studies in respect of pharmacovigilance in Nigeria has comparatively evaluated the knowledge, attitude and practice of pharmacovigilance (KAP) by community and hospital pharmacists [17-20]. In this study, we assessed KAP of PV and ADR reporting in two contiguous States in the Federal Republic of Nigeria in the belief that the data would help in providing some information that can improve drug safety in Nigeria.

\section{METHODS}

\section{Study design and setting}

The study was a descriptive cross-sectional survey carried out to evaluate the knowledge, attitude and practice of pharmacovigilance by community and hospital pharmacists in Abia and Imo States of South-Eastern Nigeria.

Available records from the Office of Directorate of Pharmaceutical Services of Abia and Imo States showed that there were altogether, 115 community pharmacists and 112 pharmacists employed in the hospitals. According to the 2006 national census, the two states have a total population of approximately 7 million. This gives a pharmacist: population ratio of 1:25,000. Each State had two tertiary hospitals for the training of medical doctors and other healthcare professionals; secondary health facilities and several privately owned pharmacies. In each of the States, there was a Federal Government of Nigeria owned tertiary health facility and an ADR Monitoring or Drug Safety Committee that was responsible for receiving cases of ADRs and forwarding confirmed cases to the National Pharmacovigilance Centre (NPC) in Abuja, the Federal Capital.

\section{Study instrument}

A 34-point pre-designed questionnaire was used for the study. The questionnaire was adapted from previous studies on knowledge, attitude, and practice of healthcare professionals and ADR-reporting [21,22] using both open and closed ended questions. Some modifications were made to the questionnaire to reflect policies and guidelines in Nigeria. Face validity and internal consistency were tested through a pilot study of 20 randomly selected pharmacists (n $=10$ each for hospital and community) and adjustments were made where necessary. Total possible score on the knowledge items was 24 (1 point per item). The maximum total score on the attitude items was 14 while the maximum total score on the practice items was 18. Correct responses to questions on knowledge, attitude and practice were graded: $0-49 \%$ (poor); $50-59 \%$ (fair); $\geq 60 \%$ (good).

\section{Sampling procedure}

In the case of the hospital pharmacists, distribution of the questionnaire was facilitated by the Heads of Department of Pharmacy at the various study sites. Distribution of the questionnaire among community pharmacists was done on a one-on-one basis after obtaining verbal consent from the respondents. Similarly, consent to participate was sought among hospital pharmacists through a brief explanatory speech delivered by the investigators at each of the study sites. The questionnaire was selfadministered and retrieved on completion same day.

\section{Statistical analysis}

Data were entered into Microsoft Excel software (2007) and then SPSS version 11.0 (SPSS, Inc. Chicago, IL) and double-checked to ensure 
accuracy. All data are presented as simple percentages or mean \pm SD.

\section{RESULTS}

\section{Demographics of participants}

Basic demographics of respondents are presented in Table 1. Out of the 227 copies of the questionnaire administered, 184 were returned out of which 169 (74.4\%) were properly completed and usable. Majority of them were less than 40 years of age and had no postgraduate education. Percentage of retuned but usable questionnaire was 54.5 and 93.9 for community and hospital pharmacists respectively.

Most community pharmacists (70.5\%) and hospital pharmacists $(82.4 \%)$ had only the minimum qualification (B.Sc, B.Pharm, PharmD) needed to practice. The remainders had additional relevant postgraduate qualifications (M.Sc, M.Pharm, and Fellowship of the West African Postgraduate College of Pharmacy).

The percentages of pharmacists with more than five years of experience were $60.7 \%$ of all community pharmacists, $88.0 \%$ of all hospital pharmacists, and $78.0 \%$ for all pharmacists.
Knowledge of pharmacovigilance by pharmacists

All respondent pharmacists were aware of the term pharmacovigilance (Table 2). This high level of awareness did not translate to good knowledge of pharmacovigilance. For example, among community pharmacists, only $41.0 \%$ knew that cohort event monitoring (CEM) was a type of active pharmacovigilance while only $24.9 \%$ of all pharmacists were aware of the national ADR reporting form (yellow form). Altogether, only $20.1 \%$ of all respondents had received training in pharmacovigilance. Pharmacists who could define pharmacovigilance correctly comprised of $52.5 \%$ (community), 73.1\% (hospital), and 65.7\% (all).

\section{Attitude of pharmacists towards pharmaco- vigilance}

Figures $1-3$ show the attitude of pharmacists towards pharmacovigilance. In general, not all pharmacists who participated in the study agreed that it was necessary to report ADRs (Figure 1). Similarly, $78.7 \%$ of community pharmacists and $79.6 \%$ of hospital pharmacists considered it important that pharmacy undergraduates should be trained on pharmacovigilance. Only $47.5 \%$ of community pharmacists agreed that ADR reporting should be mandatory for pharmacists. In contrast, $72.0 \%$ of hospital pharmacists agreed that ADR reporting should be mandatory for pharmacists.

Table 1: Demographics of respondent pharmacists

\begin{tabular}{|c|c|c|c|}
\hline & $\begin{array}{c}\text { Community } \\
\text { Pharmacists } \\
\text { N (\%) }\end{array}$ & $\begin{array}{c}\text { Hospital } \\
\text { Pharmacists } \\
\text { N (\%) }\end{array}$ & $\begin{array}{c}\text { All Pharmacists } \\
\text { N (\%) }\end{array}$ \\
\hline \multicolumn{4}{|l|}{ State of Practice } \\
\hline Abia & $21(34.4)$ & $43(39.8)$ & 64 (37.9) \\
\hline Imo & $40(65.6)$ & $65(60.2)$ & $105(62.1)$ \\
\hline \multicolumn{4}{|l|}{ Gender } \\
\hline Male & 39 (63.9) & $58(53.7)$ & $97(57.4)$ \\
\hline Female & $22(36.1)$ & $50(4.3)$ & $72(42.6)$ \\
\hline \multicolumn{4}{|l|}{ Age (years) } \\
\hline $21-30$ & $24(39.3)$ & $44(40.7)$ & $68(40.2)$ \\
\hline $31-40$ & $16(26.2)$ & $30(27.8)$ & $46(27.2)$ \\
\hline $41-50$ & $9(14.8)$ & 23 (21.3) & 32 (18.9) \\
\hline $51-60$ & $8(13.1)$ & $10(9.3)$ & $18(10.7)$ \\
\hline \multicolumn{3}{|l|}{ Marital Status } & $5(3.0)$ \\
\hline Married & $50(82)$ & $81(75)$ & $131(77.5)$ \\
\hline Single & $11(18)$ & 27 (25) & $38(22.5)$ \\
\hline \multicolumn{4}{|l|}{ Qualification } \\
\hline $\begin{array}{l}\text { B.Sc./B. } \\
\text { Pharm/Pharm D }\end{array}$ & $43(70.5)$ & 89 (82.3) & $132(78.1)$ \\
\hline $\begin{array}{l}\text { Postgraduate } \\
\text { Years of Practice }\end{array}$ & $18(29.5)$ & $19(17.6)$ & $37(22.0)$ \\
\hline $1-5$ & $14(23)$ & $23(21.3)$ & $37(22.0)$ \\
\hline$>6$ & $37(60.7)$ & $95(88)$ & $132(78)$ \\
\hline
\end{tabular}


Table 2: Knowledge-related aspects pharmacovigilance by pharmacists

\begin{tabular}{|c|c|c|c|}
\hline Variable & $\begin{array}{c}\text { Community } \\
\text { Pharmacists } \\
\text { N (\%) }\end{array}$ & $\begin{array}{c}\text { Hospital } \\
\text { Pharmacists } \\
\text { N (\%) }\end{array}$ & $\begin{array}{c}\text { All Pharmacists } \\
\mathbf{N}(\%)\end{array}$ \\
\hline Awareness of PV & $61(100)$ & $108(100)$ & $169(100)$ \\
\hline Trained & $11(18.0)$ & $23(21.3)$ & $34(20.1)$ \\
\hline Ability to define PV & $32(52.5)$ & $79(73.1)$ & $111(65.7)$ \\
\hline \multicolumn{4}{|l|}{ Knowing involves } \\
\hline i. Monitoring ADRs & $47(77.0)$ & $54(50.0)$ & $101(59.8)$ \\
\hline ii. Reporting ADRs & $53(86.9)$ & $90(83.3)$ & $143(84.6)$ \\
\hline iii. Analysing ADRs & $21(34.4)$ & $48(44.4)$ & $69(40.8)$ \\
\hline \multicolumn{4}{|l|}{ Knowing those involved in PV } \\
\hline i. Doctors & $61(100)$ & $108(100)$ & $169(100)$ \\
\hline ii. Pharmacists & $56(93.4)$ & $102(94.4)$ & $158(93.5)$ \\
\hline iii. Nurses/Midwives & $54(98.5)$ & $108(100)$ & \\
\hline iv. Med Lab Scientists & $28(45.9)$ & $76(70.4)$ & $(104(61.5)$ \\
\hline v. Patent Med Vendors & $13(21.3)$ & $32(29.6)$ & $45(26.6)$ \\
\hline vi. Herbal Med Practitioner & $22(36.1)$ & $10(9.3)$ & $32(18.9)$ \\
\hline $\begin{array}{l}\text { vii. Other trained health } \\
\text { workers }\end{array}$ & $37(60.7)$ & $66(61.1)$ & $103(61.0)$ \\
\hline \multicolumn{4}{|l|}{ Types of Active PV } \\
\hline i. CEM & $25(41.0)$ & $68(63.0)$ & $93(55.0)$ \\
\hline ii. PEM & $20(32.8)$ & 36 (33.3) & $56(33.1)$ \\
\hline iii. IMMP & $18(30.0)$ & $33(30.6)$ & $51(30.2)$ \\
\hline Best definition of ADR & $41(67.2)$ & 77 (71.3) & $118(68.8)$ \\
\hline $\begin{array}{l}\text { Phase for detection of rare ADRs } \\
\text { in clinical trial }\end{array}$ & $17(27.7)$ & $40(37.0)$ & $57(33.7)$ \\
\hline $\begin{array}{l}\text { Major risk factor for ADR to } \\
\text { occur }\end{array}$ & $55(90.2)$ & $90(83.3)$ & $145(85.8)$ \\
\hline $\begin{array}{l}\text { Reason for withdrawal of } \\
\text { Avandia }\end{array}$ & $36(59.0)$ & $(80(74.1)$ & $116(68.6)$ \\
\hline $\begin{array}{l}\text { Reason for withdrawal of } \\
\text { phenformin }\end{array}$ & $31(50.8)$ & $57(52.8)$ & $88(52.1)$ \\
\hline $\begin{array}{l}\text { Awareness of NAFDAC yellow } \\
\text { form }\end{array}$ & $14(23.0)$ & $28(26.0)$ & $42(24.9)$ \\
\hline
\end{tabular}

CEM, cohort event monitoring; PEM, prescription event monitoring; IMMP, intensive medicines monitoring programme; NAFDAC, National Agency for Food and Drug Administration and Control. Avandia ${ }^{\circledR}=$ rosiglitazone

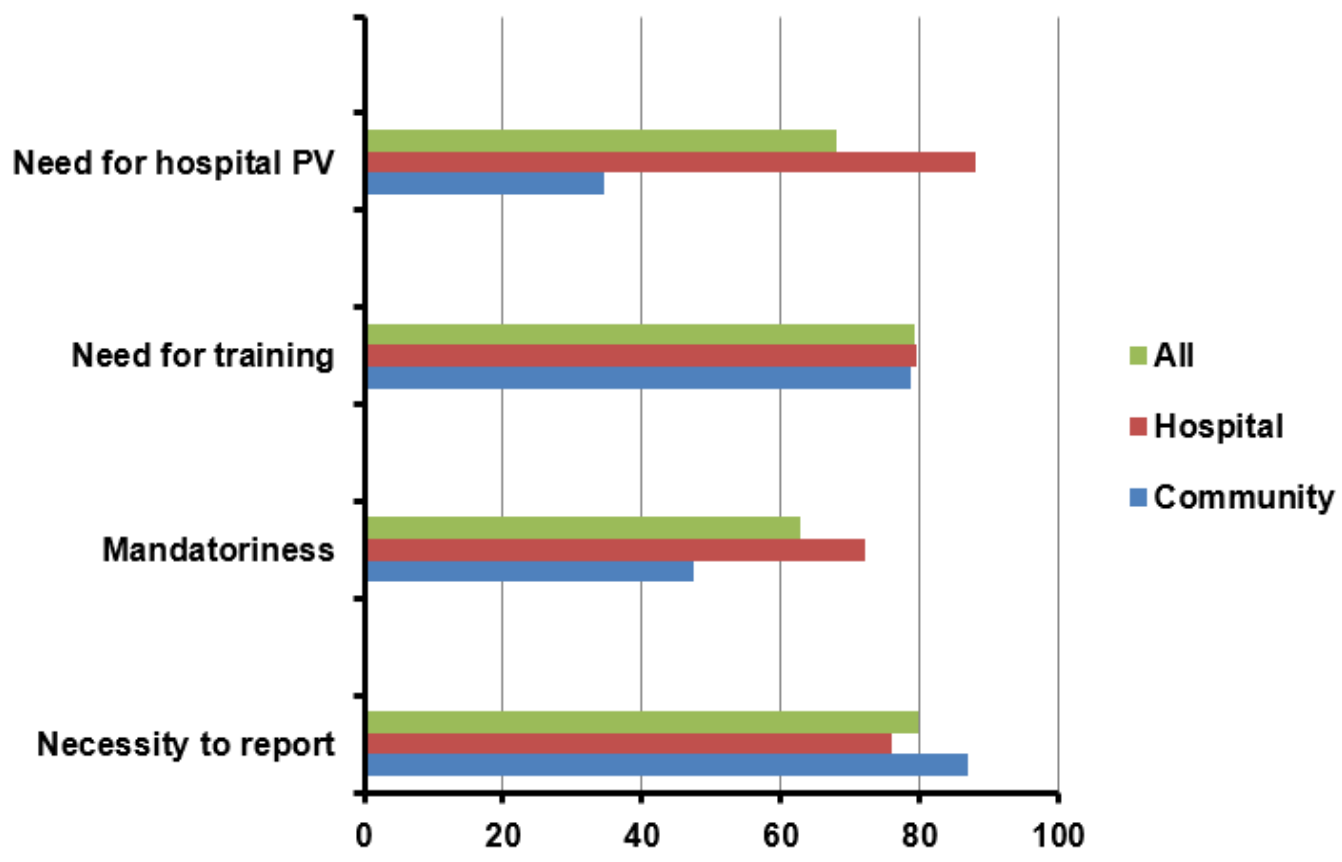

Figure 1: Percentages of pharmacists that responded "YES" to attitude related questions on key aspects of ADR reporting. Hospital pharmacists, $N=61$; Community pharmacists, $N=108$ 


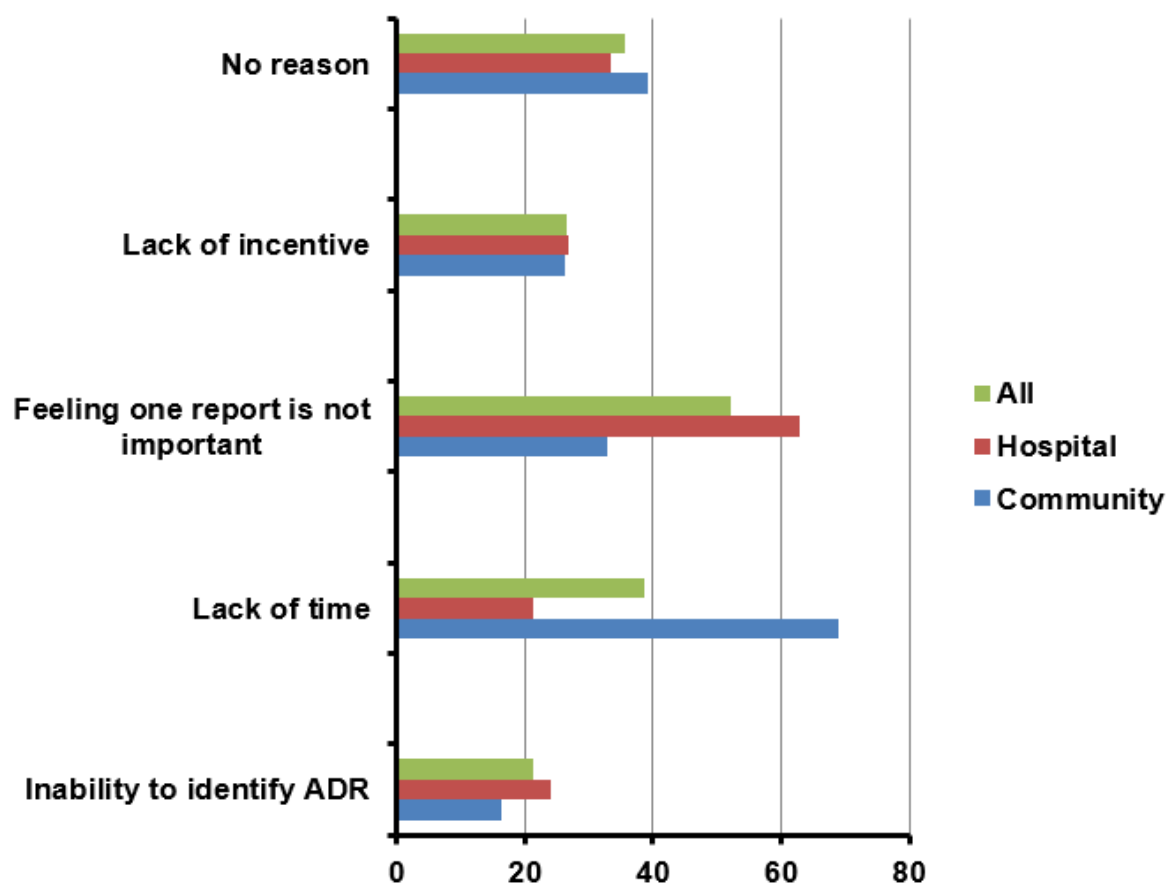

Figure 2: Pharmacists that responded to the attitude-related question of why ADRs were not reported. Hospital pharmacists, $\mathrm{N}=61$; Community pharmacists, $\mathrm{N}=108$

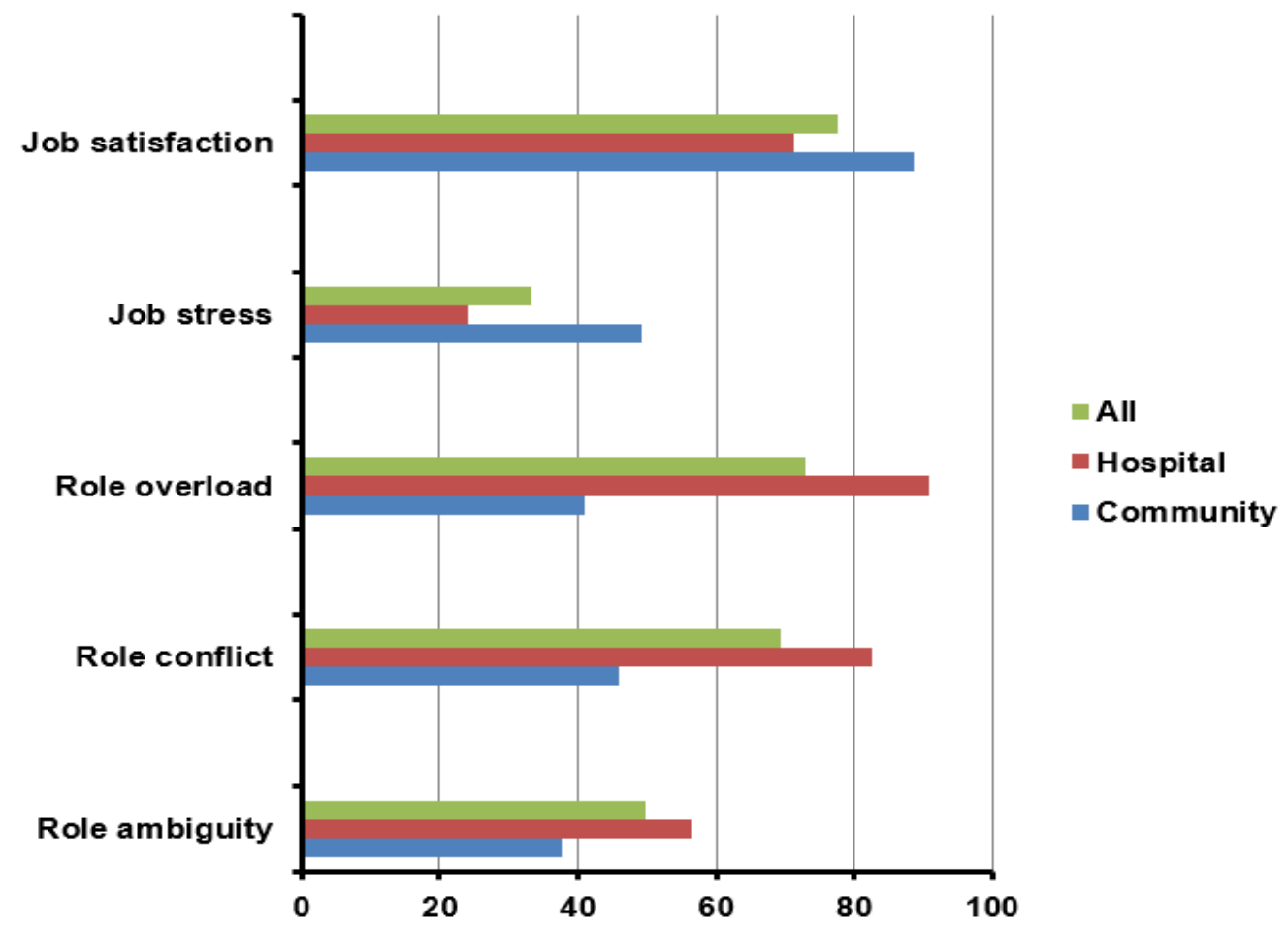

Figure 3: Pharmacists that responded to attitude related question of how reporting ADRs can affect their other professional responsibilities. Hospital pharmacists, $\mathrm{N}=61$; Community pharmacists, $\mathrm{N}=108$

A number of factors accounted for poor reporting of ADRs but lack of time was the reason given by most community pharmacists $(69.0 \%)$, while the excuse that one report coming from them was not sufficient to make impart was given by $63.0 \%$ of hospital pharmacists. Lack of incentive was the reason given by $26.6 \%$ of all the pharmacists.
No reason was given by $35.0 \%$ of all pharmacists (Figure 2).

In Figure 3, most pharmacists (77.5\% of all) agreed that reporting ADR would give them selfsatisfaction and fewer pharmacists (33.1\% of all) considered that it would result in more job stress. 
The major considerations for hospital pharmacists were role overload (90.7\%) and role conflict with other staff in the hospitals (82.5\%). Out of all pharmacists $49.7 \%$ considered involvement in pharmacovigilance activities as role ambiguity.

\section{Practice of PV by pharmacists}

Regarding the practice related questions (Table 3), $57.4 \%$ of community pharmacists and $82.4 \%$ of hospital pharmacists had encountered an ADR in the course of practice but only $26.2 \%$ of community pharmacists and $23.1 \%$ of hospital pharmacists had ever reported an ADR. This is in spite of the fact that $72.1 \%$ of community pharmacists and $88.0 \%$ of hospital pharmacists had seen an ADR reporting form. Altogether, $24.3 \%$ of such reports were sent to NPC by the pharmacists. Very few community $(13.1 \%)$ and hospital $(16.7 \%)$ pharmacists could explain an approach to preventing ADR occurrence. The majority of respondents (87.6\%) sourced their information on ADR from textbooks.

\section{Percentage scores of pharmacists on questions relating to KAP}

Hospital pharmacists had higher percentage scores for knowledge, attitude, and practice, than the community pharmacists (Table 4).
Table 4: Percentage score on questions related to knowledge, attitude and practice by pharmacists in the two practice settings

\begin{tabular}{lcc}
\hline Variable & Community & Hospital \\
\hline Knowledge (24) & $31.4 \pm 17.8$ & $58.9 \pm 32.1$ \\
Attitude (14) & $30.2 \pm 13.8$ & $62.4 \pm 28.4$ \\
Practice (18) & $26.6 \pm 15.0$ & $49.2 \pm 29.1$ \\
\hline
\end{tabular}

\section{DISCUSSION}

This study has shown that while all respondent pharmacists in the two states were aware of PV, only few had reported an ADR. The study also shows that not all pharmacists saw the need to report ADRs. The hospital pharmacists were superior to their community counterparts in KAP score.

There was high awareness of the concept of pharmacovigilance (PV) by all pharmacists in the two States. The level of awareness of PV by hospital pharmacists was found to be low [18] and low level of awareness was reported for community pharmacists in Lagos State [20].The increase in awareness of the concept may be attributed to more recent regular broadcast of PV jingles by the National Agency for Food and Drug Administration and Control (NAFDAC) on news media. Although awareness was high among the

Table 3: Practice-related aspects of pharmacovigilance by pharmacists

\begin{tabular}{|c|c|c|c|}
\hline Variable & $\begin{array}{c}\text { Community } \\
\text { pharmacists } \\
\text { N (\%) }\end{array}$ & $\begin{array}{c}\text { Hospital } \\
\text { pharmacists } \\
\text { N (\%) }\end{array}$ & $\begin{array}{c}\text { All Pharmacists } \\
\mathbf{N}(\%)\end{array}$ \\
\hline Those who had seen an ADR & $35(57.4)$ & $89(82.4)$ & $124(73.4)$ \\
\hline $\begin{array}{l}\text { Frequency of seeing ADRs } \\
\text { i. Often } \\
\text { ii. Regularly } \\
\text { iii. Rarely } \\
\text { iv. Never }\end{array}$ & $\begin{array}{c}13(21.3) \\
7(11.5) \\
15(24.6) \\
26(42.6)\end{array}$ & $\begin{array}{l}11(10.2) \\
31(28.7) \\
47(43.5) \\
19(17.6)\end{array}$ & $\begin{array}{l}24(14.2) \\
38(22.5) \\
62(36.7) \\
45(26.6)\end{array}$ \\
\hline $\begin{array}{l}\text { Those who had seen ADR form } \\
\text { Those who had reported an ADR to NPC } \\
\text { Suggestion to prevent ADRs } \\
\text { Ability to explain suggestion }\end{array}$ & $\begin{array}{l}44(72.1) \\
16(26.2) \\
39(63.9) \\
8(13.1)\end{array}$ & $\begin{array}{l}95(88.0) \\
25(23.1) \\
64(59.3) \\
18(16.7)\end{array}$ & $\begin{array}{l}139(82.3) \\
41(24.3) \\
41(24.3) \\
26(15.4)\end{array}$ \\
\hline $\begin{array}{l}\text { Preference for ADR update } \\
\text { i. Internet } \\
\text { ii. Textbooks } \\
\text { iii. Journals } \\
\text { iv. Pharmaceutical sales reps } \\
\text { v. Drug information leaflets } \\
\text { vi. National PV newsletter } \\
\text { vii Others }\end{array}$ & $\begin{array}{l}28(45.9) \\
57(93.4) \\
18(29.5) \\
50(82.0) \\
32(52.5) \\
15(24.6) \\
36(59.0) \\
\end{array}$ & $\begin{array}{c}63(58.3) \\
91(84.3) \\
27(25.0) \\
63(58.3) \\
43(39.8) \\
28(25.9) \\
55(51) \\
\end{array}$ & $\begin{array}{c}91(53.9) \\
148(87.6) \\
45(26.6) \\
91(53.9) \\
75(44.4) \\
43(25.4) \\
91(53.9)\end{array}$ \\
\hline
\end{tabular}


pharmacists, the requisite knowledge required to participate effectively in PV activities seemed to be lacking. For example, not all pharmacists could define $\mathrm{PV}$ reasonably and about half of all the respondents did not know that cohort event monitoring is a type of active pharmacovigilance. Interestingly, only a small percentage of pharmacists had seen the individual case reporting form (ADR reporting form, Yellow Form) issued by the National Pharmacovigilance Centre (NPC) that is a unit of NAFDAC. Conversely, many more pharmacists in the two practice settings had seen an ADR reporting form which could have been the same NAFDAC form except that the colour was lost through photocopying. In comparative terms, hospital pharmacists were better knowledgeable than their community counterparts. This may be due to the fact that the hospital environment is more formal and drug safety committees, hospital formulary committees and clinical presentations often highlight the need for PV.

The community pharmacy is often the first port of call by patients because of its ease of accessibility [10]. Therefore, it should be expected that cases of ADRs would be easily seen by practitioners who should then report them to the NPC. This study has shown that although a high percentage of community pharmacists saw the need to report ADRs, they complained of lack of time. It seems that community pharmacists considered other aspects of practice and sales turnover higher than reporting of ADRs. A similar study has shown that $50 \%$ of hospital and community pharmacists in a province of South Africa considered reporting to be time consuming [23]. The time factor may explain why $47.5 \%$ of community pharmacists as against $72 \%$ of hospital pharmacists suggested that reporting ADRs should be mandatory if success is to be attained. Interestingly, all the pharmacists believed that participating in PV activities could enhance job satisfaction. Despite this, issues such as job overload, role conflict and role ambiguity are potential factors that could negatively influence participation in PV particularly among hospital pharmacists. For example, incidences of role conflict between pharmacists and doctors have been reported [24]. Lack of communication has been identified as a cause of poor doctors-pharmacists working relationship that inter-professional education could solve [25]. Although it is considered important [26], pharmacists in the two practice settings did not consider giving incentives a major stimulus for ADR reporting. That $33.3 \%$ of hospital pharmacists and $39.3 \%$ of community pharmacists did not have reasons for not reporting ADRs underscores the poor attitude towards PV that should be addressed.

The practice of $\mathrm{PV}$ is low by both hospitals and community pharmacists as only $23.1 \%$ and $26.2 \%$ respectively had ever reported an ADR. This is not consistent with the high numbers of pharmacists in the two practice settings that had seen an ADR in practice. Low level of reporting has also been reported by others [20,27]. The poor attitude to PV earlier highlighted may explain why only few pharmacists had reported ADRs in spite of the fact that ADR reporting forms can be downloaded from NAFDAC website.

This study also shows a worrisome trend in the referencing sources for ADRs as most of the pharmacists updated their knowledge from textbooks. It is generally known that textbooks are usually not very current with information on drugs [28]. This may be due to the time lag between assemblage of manuscripts and eventual publishing of the textbook. A high percentage of the community pharmacists $(82.0 \%)$ also depended on pharmaceutical sales representatives for their information on ADRs. Representatives of companies may not always be balanced in the information that they give about their products [29]. In addition, acceptance of promotional items from representatives could result in failure of pharmacists to report ADRs associated with the companies [30].

In a study in India, training was found to correlate positively with pharmacovigilance activities by health workers [31].In order for professionals to be good signal generators, it is important to train and re-train them on safety issues with particular reference to the drugs that are commonly used in practice[32].Qualifications in terms of additional degrees obtained after the basic B.Pharm or PharmD degree is similar to further training and the curricular for postgraduate programmes often contain PV related topics. Therefore continuous informal training and acquisition of postgraduate qualification may be used to address the flaws in knowledge, attitude and practice.

\section{CONCLUSION}

Although there was a high level of awareness of PV by pharmacists in the two South-Eastern States of Nigeria, the attitude and practice through ADR reporting were very poor. This implies that measures such as making reporting form available to all pharmacists and continuously reminding them through meetings and lectures, that reporting ADRs is ethical and mandatory should be taken. This will further 
strengthen drug safety in the two states. The major limitations to the study include the nonevaluation of the quality of ADR reported by the few pharmacists and the inability of the investigators to review patient charts to ascertain the level of adverse drug events in the hospitals and pharmacies.

\section{DECLARATIONS}

\section{Acknowledgement}

The authors are grateful to Heads of Pharmacy Departments in the hospitals and proprietors of all the community pharmacies for their cooperation. The study was part of the PharmD dissertation by JAU in the University of Benin, Benin City, Nigeria and was funded by the authors.

\section{Conflict of Interest}

No conflict of interest associated with this work.

\section{Contribution of Authors}

The authors declare that this work was done by the authors named in this article and all liabilities pertaining to claims relating to the content of this article will be borne by them.

\section{REFERENCES}

1. Bonn D. Adverse drug reactions remain a major cause of death. Lancet 1998; 351: 1183.

2. Lazarou J, Pomeranz BH, Corey PN. Incidence of adverse drug reactions in hospitalised Patients. A metaanalysis of prospective studies. JAMA 1998; 279: 1200 1205.

3. Shepherd G, Mohorn P, Yacoub K, May DW. Adverse drug reaction deaths reported in United State vital statistics, 1999-2006. Ann Pharmacother 2012; 46: 169175.

4. Wu C, Bell CM, Wodchis WP. Incidence and economic burden of adverse drug reactions among elderly patients in Ontario emergency departments: a retrospective study. Drug Saf 2012; 35: 769-781.

5. Sultana J, Cutroneo P, Trifio G. Clinical and economic burden of adverse drug reactions. I Pharmacol Pharmacother 2013; 4: S73-77.

6. Ernst FR, Grizzle AJ. Drug-related morbidity and mortality: updating the cost-of-illness model. J Am Pharm Assoc 2001; 41: 192-199.

7. Osakwe Al, Suku C, Obianonwo A, Fadaka E. Drug regulation and pharmacovigilance in Nigeria. In: Rosalyn C. King RC, Oqua DAN, Agu KA, editors. GHAIN PROJECT: Pharmacovigilance for Antiretroviral Drugs Training for Health Care Professionals. Silver Spring
Howard University Continuing Education PACE Center 2009.p. 4-10.

8. Akinyandemu $O$, Akinyandemu A. Irrational use and nonprescription sale of antibiotics in Nigeria: a need for change. J Scientific Innovative Res 2014; 3: 251-257.

9. Strengthening Pharmaceutical Systems (SPS) Program. Safety of Medicines in Sub-Saharan Africa: Assessment of Pharmacovigilance Systems and their Performance. Submitted to the US Agency for International Development by the Strengthening Pharmaceutical Systems (SPS) Program. Arlington, VA: Management Sciences for Health 2011 [cited 2017 Mar 8]. Available from: http://apps.who.int/medicinedocs/en/d/Js19152en/.

10. World Health Organization (WHO). The role of the pharmacist in the healthcare system. Report of a consultative Group, New Delhi India 13 -16 Dec 1988 and report of a WHO meeting Tokyo Japan; 31st August - 3 September 1993 [cited 2017 Apr 6]. Available from:http://apps.who.int/medicinedocs/en/d/Jh2995e/.

11. Barber N, Smith F, Anderson S. Improving the quality of healthcare: the role of pharmacists. Qual Health Care 1994; 3: 153-158.

12. Lexchin J. Is there still a role for spontaneous reporting of adverse drug reactions? CMAJ 2006; 174; 191-192.

13. World Health Organization (WHO). The Safety of Medicines in public health programs: Pharmacovigilance an essential tool, 2006 [cited 2017 Apr 6]. Available from: http://apps.who.int/iris/handle/ $10665 / 43384$.

14. Goldman SA. Communication of medical product risk: how effective is effective enough? Drug Saf 2004; 27: 519-534.

15. Decima Research Inc. Public opinion survey on key issues pertaining to post-market surveillance of marketed health products in Canada: final report. Ottawa: Health Canada 2003; Report no. POR 298-02.

16. Pirmohamed M, Breckenridge AM, Kittering NR, Park BK. Adverse Drug Reactions. BMJ 1998; 316: 1295-1298.

17. Fajemirokun TO, Femi-Oyewo MN, Osunsanya OY. Adverse drug reactions, reporting at the Olabisi Onabanjo University Teaching Hospital. West Afr J Pharmacy 2004; 18: 63-66.

18. Ukwe CV, Aguwa CN. Pharmacists, Knowledge and Attitude towards Adverse Drug Reaction (ADR) Reporting in Nigeria's Tertiary Hospitals. Nig $J$ Pharmacy 2006; 12: 50-53.

19. Okezie EO, Olufumilayo I. Adverse drug reaction reporting by physicians in Ibadan, Nigeria. Pharmacoepidemiol Drug Saf 2008; 17: 517-522.

20. Oreagba AI, Ogunleye OJ, Olayemi SO. The knowledge, perception and practice of pharmacovigilance amongst Community pharmacists in Lagos state, south west Nigeria: Pharmacoepidemiol. Drug Saf 2011; 20: 30-35.

21. Belton KJ, Lewis SC, Payne S, Rawlins MD, Wood SM. Attitudinal survey of adverse drug reaction reporting by medical practitioners in the United Kingdom. $\mathrm{Br} \mathrm{J}$ Clin Pharmacol 1995; 39: 223-226.

Trop J Pharm Res, May 2018; 17(5): 944 
22. Ekman E, Backstrom M. Attitudes among hospital physicians to the reporting of adverse drug reactions in Sweden. Eur J Clin Pharmacol 2009; 65: 43-46.

23. Joubert MC, Naidoo P. Knowledge, perceptions and practices of pharmacovigilance amongst community and hospital pharmacists in a selected district of North West Province, South Africa. Health SA Gesondheid 2016; 21: 238-244.

24. Mesler MA. Boundary encroachment and task delegation: clinical pharmacists on the medical team. Sociol Health Illness 2008; 13: 310-331.

25. Gallagher RM, Gallagher HC. Improving the working relationship between doctors and pharmacists: is interprofessional education the answer? Adv Health Sci Educ Theory Pract 2012; 17: 247-257.

26. Feely J, Moriarty S, O'Çonnor P. Stimulating reporting of adverse reactions by using a fee. Br Med J 1990; 300: 22-23.

27. Umar MT, Bello SO, Chika A, Oche OM. Attitude of nurses and pharmacists on adverse drug reactions reporting in selected hospitals in Sokoto, Northwest Nigeria. J Res Pharm Pract 2016; 5: 219-221.
28. Jeffery R, Navarro T, Lokker C, Haynes RB, Wilczynski NL, Forjou G. How current are leading evidence-based medical textbooks? An analytical survey of four online textbooks. J Med Internet Res 14: e175.

29. Tejani AM, Loewen $P$, Bachand $R$, Harder $C K$. Pharmacists' Perceptions of the Influence of Interactions with the Pharmaceutical Industry on Clinical DecisionMaking. Can J Hosp Pharm 2015; 68: 378-385.

30. Zaki NM. Pharmacists' and physicians' perception and exposure to drug promotion: a Saudi study. Saudi Pharm J 2014; 22: 528-536.

31. Gupta $S K$, Nayak RP, Shivaranjani R, Vidyarthi SK. A questionnaire study on the knowledge, attitude, and the practice of pharmacovigilance among the healthcare professionals in a teaching hospital in South India. Perspect Clin Res 2015; 6: 45-52.

32. Ozolua RI. Understanding signals and benefit-risk determinations: In: Rosalyn C. King RC, Oqua DAN, Agu KA, Eds. Ghain Project: Pharmacovigilance for Antiretroviral Drugs Training for Health Care Professionals. Silver Spring Howard University Continuing Education PACE Center 2009; pp 144-149. 